\title{
El parque de Allende, los parques de Aylwin: proyectos urbanos y discursos políticos
}

Pía Montealegre. Universidad de Chile, Santiago, Chile.

RESUMEN | Este artículo analiza comparativamente dos momentos históricos en los que el parque urbano fue asociado a explícitos discursos políticos en Chile. En un extremo, la Unidad Popular (UP) y su manifiesto cometido de hacer del parque Cousiño un sitio de recreación obrera. En el otro extremo y con el retorno de la democracia, un programa de parques públicos impulsado por el Ministerio de Vivienda y Urbanismo. Mientras la primera operación fue la implantación de un modelo, la segunda indagó en la aplicación de una estrategia de diseño participativo. En ambos casos, el parque que buscó crear el Estado estuvo comandado a encarnar en el espacio las particularidades de cada momento histórico. El interés de esta comparación radica en, por una parte, comprender cómo la provisión de parques urbanos adaptó sus cometidos políticos durante el siglo xx; por otra, entender los alcances simbólicos de una obra pública en el entramado de los imaginarios urbanos.

PALABRAS CLAVE | espacio público, política urbana, historia urbana.

ABSTRACT | Using a comparative method, this paper analyzes two case studies that illustrate the relationship between urban parks and political discourses in Santiago de Chile. The first case examines Parque O'Higgins, a park developed to transform the bourgeois Parque Cousiño, into a proletarian recreation facility during the socialist government of Unidad Popular (1970-1973). The second case analyzes the public parks program spearheaded by the Chilean Ministry of Housing and Urbanism after the return of democracy in 1990. While Parque O'Higgins proposed a new design and execution model for public space, the parks of the political transition implemented a participatory design strategy. In both cases, the state shaped these parks to reflect the particularity of each historical moment. This comparative study is relevant because it helps understand how the Chilean state's vision for public green areas changed throughout the 20th century and illuminates the urban imaginaries behind public space.

KEYWORDS | public space, urban policy, urban history. 


\section{El parque como instrumento político}

El correlato patente entre la forma del poder y la forma del espacio ha sido un tópico "clásico" (Ballent \& Gorelik, 2000) y ampliamente recurrido en la interpretación de la ciudad. Ineluctablemente está influido por la obra de Foucault (1975, 1978a), quien ha planteado consideraciones acerca de la arquitectura como una técnica de gobierno (Foucault, 1984) o la evolución desde un urbanismo disciplinario a un ordenamiento de seguridad (Foucault, 1978b). Las figuras foucaultianas encuentran una resonancia evidente en aquellos espacios que son fruto de estructuras de control especialmente elocuentes, como regímenes autoritarios, dominaciones económicas o colonialismos, donde la forma del espacio se vuelve una representación de la detención de ese poder. Sin embargo, la relación entre espacio y poder está también presente, toda vez que el espacio es un instrumento de discurso en la agenda política. Como observan Ballent y Gorelik (2000), la "estética de la política" es reconocible desde los fascismos a los gobiernos democráticos. Ballent (2005) la analizó también en la vivienda peronista, usada como un vehículo de aproximación al gusto de la clase media. Puede ser leída en múltiples estrategias de mejoramiento urbano no exentas de contenidos más amplios sobre ciudadanía y democracia, como la instrumentalización de la arquitectura en tanto detonante de cambio social en el programa de parques-biblioteca de Medellín (Capillé, 2018). Como plantea Findley (2005), la arquitectura puede ser concebida como una herramienta que encarna y acelera una agenda social, interviniente aun en la redistribución del poder.

En Latinoamérica, diversos estudios han construido estos relatos sobre espacio y poder, específicamente las relaciones entre política y técnica. Este trabajo tributa en parte a aquella línea, aunque -como se verá a continuación- el carácter artesanal y adaptativo de los proyectos aquí analizados pueda hacer que el término "técnica" parezca en exceso rígido e institucional para transferirlo a ellos. No obstante, la interpretación del concepto no se refiere aquí a su acepción relacionada con la fabricación material o el aparataje disciplinar, sino a la interpretación foucaultiana de la política como técnica para intervenir en una ciudad. Foucault (1978b) señala que la noción moderna de ordenamiento territorial no es ya un urbanismo disciplinario que se basa en la actuación de la forma sobre un espacio vacío, sino "un proyecto, una técnica política que se dirige al medio" (p. 44). Técnica, entonces, comprendida como un concepto que también entreteje producto y acción, forma y programa.

El parque urbano es un instrumento de la política en el sentido más amplio de la frase. En su acepción más literal, es una herramienta del urbanismo que integra la batería de operaciones con las que se hace y se actúa sobre la ciudad. Pero, también, es un artefacto mediante el cual se materializan en el espacio construido las ideas de la esfera política, como ya ha señalado con mayor profundidad y precisión conceptual Adrián Gorelik (1998) en su ya clásica tesis sobre el espacio público de Buenos Aires. En otras palabras, el parque es una herramienta transformativa, pero también un sensor historiográfico, y su interpretación permite hacer una lectura de la política y cultura urbanas de un determinado momento. Siguiendo esta hipótesis metodológica es que en este artículo se busca indagar en dos periodos en los cuales el parque urbano recibe improntas de un momento político específico. 
Los objetivos prácticos primordiales que acompañaron el surgimiento del parque urbano en la Revolución Industrial pueden resumirse en dos. Por una parte, el servir como una provisión higiénica, entendiendo el valor curativo que se otorgaba a la naturaleza antes de las teorías microbianas. El verde urbano consiguió una prioridad funcional por el rol que se le atribuía en el combate de las enfermedades que amenazaban la integridad de la fuerza laboral. Así, en el Reino Unido, por ejemplo, sesionó antes un Real Comité de Paseos Públicos (1833) que uno de vivienda (1884), y solo en 1855 las investigaciones de John Snow relacionaron las epidemias de cólera con las redes de suministro de agua, poniendo en evidencia la relevancia de la infraestructura sanitaria. Antes de ello, se veían los "pulmones verdes" como el instrumento más efectivo de salud urbana. Por otra parte, surgió como una provisión reformista: el parque era visto como un elemento que fortalecía la moral de las clases obreras y, en la metáfora de la máquina productiva, la recreación era un engranaje más. Con el verde urbano se apaciguaban las ideas revolucionarias, especialmente al contrarrestar las condiciones paupérrimas de vivienda de la ciudad industrial. Muchos otros objetivos simbólicos acompañaron el surgimiento de parques y paseos, la mayoría relacionados con la construcción de un modelo de salons verts (Ernouf \& Alphand, 1886), o la proyección en el espacio público de las formas de recreación burguesas. Si bien esto ha sido el correlato del imaginario decimonónico en su versión más vanidosa y superficial, el paseo público resultó ser también una útil herramienta para construir una imagen de modernidad urbana que se extendía y replicaba como un sistema estandarizado (Choay, 1975). Fue también utilizado como amenidad para el desarrollo inmobiliario desde muy tempranas expresiones, como en el Regent's Park (1835) y el Birkenhead Park (1847), incorporándose el verde a la paleta del planeamiento moderno, tanto en el modelo de ciudad jardín a comienzos del siglo xx como en el urbanismo desarrollista tributario del movimiento moderno.

Pero, más allá de las funciones asignadas al parque en la historia de la agenda urbana, se busca entender aquí cómo los discursos políticos puntuales son representados. Interesa detectar qué se traspasa de ellos al espacio, cómo se materializan en formas construidas y qué de la especificidad del momento histórico se traduce en el lugar. Entender, por ejemplo, cómo un parque puede encarnar asuntos tan diversos y señeros como la reivindicación popular o la reparación del trauma. A esto obedece la elección de los dos momentos históricos que comparecen aquí y que enmarcan el oscuro periodo de la dictadura de Pinochet. En un margen, la remodelación que acomete el gobierno de Allende (1970-1973) sobre el parque Cousiño siguió un objetivo declarado de reclamación obrera del lugar. El Central Park santiaguino se había originado en 1872 como insignia del paseo oligarca (Montealegre, 2017) y su transformación en parque popular, ahora denominado parque O'Higgins, no estaba exenta de subversión, incluyendo el cambio de su nombre que, hasta entonces, honraba al magnate que había sido su principal benefactor. En el otro margen y ya con el retorno de la democracia, en 1990 el gobierno de Patricio Aylwin, a través del Ministerio de Vivienda y Urbanismo (MINVU), implementó un ambicioso Programa de Parques Urbanos. Este fue concebido como una herramienta de reparación espacial, apuntando específicamente a la transformación de sectores cuya degradación 
y postergación se impugnaban a la política urbana de la dictadura. Tanto el parque de Allende como los parques de Aylwin son representativos de una visión local, paulatina y adaptada de discursos políticos mayores. Así, se habla del gobierno de Allende como la "Vía Chilena al Socialismo" y del periodo que sucedió al régimen de Pinochet como la "Transición a la Democracia".

Un proyecto de remodelación y un programa de parques son, sin duda, objetos distintos. Para homologarlos, han sido interrogados respecto a sus relaciones con los discursos políticos, más que en sus lógicas proyectuales internas. Para ambos casos se ha recurrido a entrevistas con los actores y, a partir de ello, al análisis selectivo de documentos de trabajo, discursos y prensa escrita. Mientras lo que se expone del caso del parque O’Higgins (ex Cousiño) es el resultado de una investigación monográfica ya concluida (Montealegre, 2010), el estudio del Programa de los años noventa es un trabajo aún en curso, cuya delineación ha sido bastante influida por las posibilidades hermenéuticas que arrojó el primer estudio. Del mismo modo, el hecho de que para la Transición resulte ineludible el contradiscurso respecto a las políticas de la dictadura, ha permitido poner el parque de la Unidad Popular en relación con un espectro más amplio de la agenda pública histórica. Las políticas urbanas en Chile han estado subordinadas a las políticas de vivienda, y son estas últimas las que, a lo largo del siglo xx, determinaron la configuración de la periferia de la ciudad y las problemáticas de los sectores populares. De cierta forma, los parques vienen a apoyar, si no una agenda de ciudad, al menos una visión de política urbana cuyo núcleo es la dotación de vivienda.

\section{El modelo de parque popular}

El gobierno de Allende heredó la política de vivienda urbana que desde 1965 se había organizado con la creación del MINvu y sus departamentos ejecutores: la Corporación de Mejoramiento Urbano (CORMu) o la Corporación de la Vivienda (CORvi, que existía desde 1959), la Corporación de Servicios Habitacionales (CorHABIT) y la Corporación de Obras Urbanas (COU), creada en 1967. La CORvi era el organismo destinado a la construcción de viviendas; la CORHABIT, de distribuirlas; la COU, de las obras civiles de redes y servicios; y la CORMu tenía una función urbanizadora más ambiciosa y compleja, con amplias atribuciones para intervenir la ciudad. A pesar de esta división, las funciones se superponían y, en la práctica, todas las corporaciones tenían competencias amplias y similares (Raposo, 2001). Se trataba de organismos que tenían el carácter de empresas públicas que gestionaban el aparato urbano en todas sus etapas. La CORMu era el organismo que mejor representaba una visión racionalista y de ordenamiento integral de la ciudad (Raposo \& Valencia, 2004). Estaba llamada a realizar proyectos de renovación o mejoramiento, por lo que priorizaba la acción sobre áreas centrales o consolidadas más que el desarrollo en extensión.

Además de esta estructura institucional, el gobierno de la up heredó un importante déficit de unidades habitacionales que se acumulaba de administraciones anteriores. A su vez, el mismo gobierno hizo un reconocimiento de la vivienda como un derecho, lo que produjo un incremento en las presiones sociales y un 
proceso masivo de ocupación de terrenos. Así, hacia 1971 se estimaba que el 10\% de la población de Santiago residía en campamentos informales, es decir, sin urbanización ni estructura de propiedad (Hidalgo, 2004). Como señala el autor, el patrón de localización de dichos conglomerados, acoplados a los desarrollos formales de las políticas anteriores, comenzaba a formar zonas homogéneas de vulnerabilidad, o lo que se ha denominado como "territorios de la vivienda social" (Hidalgo, 2004, p. 224). Según Miguel Lawner (2008), director de la CoRMu durante el gobierno de Allende, el déficit se encumbraba a las 500.000 unidades y solo en Santiago vivían más de 60.000 familias en campamentos.

A pesar de la abultada necesidad de vivienda, la cormu no apuntó a la sola provisión cuantitativa, sino que se condujo siguiendo uno de sus principios: el concebir el espacio urbano como un correlato del desarrollo social (CORMU, 1971a). Esto se materializaba mediante dos acciones tendientes a corregir la segregación en la ciudad: la recuperación de áreas centrales, y la provisión de espacios públicos en los proyectos habitacionales. En consonancia con estas premisas, el propio Allende le encargó a la CORMu la transformación del parque Cousiño - un terreno de 80 hectáreas ubicado en el corazón de Santiago y que se encontraba en un deplorable estado de conservación- en un nuevo modelo de parque popular. Un siglo antes, el parque había sido habilitado sobre el antiguo Campo de Marte de la ciudad, como la obra filantrópica de un importante empresario chileno, Luis Cousiño, en honor al cual el espacio fue nombrado. En su versión original, el parque Cousiño era el característico parque encarrozado y elitista del siglo xIx, ideado como una amenidad urbana que se encadenaba con el desarrollo inmobiliario de nuevos barrios palaciegos. Sin mucho éxito, en el parque Cousiño se trató de restringir y disciplinar los hábitos de recreación popular, que se desplegaban tradicionalmente en ese predio, incluso antes de que fuera un terreno de ensayo militar (Montealegre, 2017). Una de las primeras operaciones que buscó revertir el pasado oligarca del lugar y devolverlo a su tradición original, fue cambiar el nombre del industrial benefactor por el del héroe de la Independencia Bernardo O’Higgins.

La relación de la CORMu con las áreas verdes había quedado sellada en una reunión que sostuvieron sus directivos con los trabajadores del parque Metropolitano (cerro San Cristóbal), a pocos días de asumido el gobierno. Como relata el mismo Lawner, ${ }^{1}$ los obreros del parque lo llevaron hasta la cima Chacarillas y le mostraron el potencial de dos estanques de riego en desuso para convertirse en una piscina popular. El proyecto y obra se inauguró a medio acabar - pero con mucho éxito- tan solo tres meses después, con una capacidad para 1.500 personas y un sistema de arriendo de trajes de baño (Figura 1). Así surgió la Oficina de Parques y Jardines al amparo de la cormu, con los trabajadores del parque Metropolitano empoderados y la presencia del arquitecto Carlos Martner, quien continuó desarrollando también el proyecto de Chacarillas. La iniciativa se expandió a una tácita política de espacios públicos destinados a la clase trabajadora, que terminó en proyectos tan particulares como el programa de balnearios populares (Balpop). Este consistía en una red de aproximadamente cuarenta centros vacacionales, cada uno con capacidad para 
unas quinientas personas y con una programación muy detallada respecto a su uso eficiente. Destinado a los sindicatos de la Central Unitaria de Trabajadores (CUT), se planificaba extender el programa por playas y ríos de todo el territorio nacional. Se llegó a construir solo una veintena, aunque se estimaba que, para cubrir la demanda, se requeriría llegar a unos trescientos. ${ }^{2}$ La Dirección de Planificación de Equipamiento Comunitario (DPEC), organismo dependiente del MINVU, fue la encargada de realizar estos centros recreacionales, otras habilitaciones de balnearios, centros sociales modulares e instalaciones pensadas para el encuentro y esparcimiento. Se asoció a la Dirección de Deportes y Recreación para coordinar las estrategias de creación y programación de estos espacios, cuyo uso nunca fue espontáneo. Esta revisión ampliada que se tenía del concepto de recreación sirve para ilustrar cómo el tiempo libre era concebido como parte de la estructura de los derechos laborales. El ocio era comprendido así integrado en la estructura productiva y debía seguir las mismas reglas de economía y eficacia. Paralelamente a estas iniciativas de origen ciudadano, se bosquejó un ambicioso programa de áreas verdes, que fue encargado directamente por inquietud del presidente Allende y que, además de la remodelación del parque O’Higgins, contemplaba otras intervenciones en el cerro San Cristóbal, en la Quinta Normal, un balneario en el Mapocho, una piscina en La Dehesa y otros parques en regiones. Para la cormu (1971b), la falta de equidad en la proporción de áreas verdes disponibles en el sector oriente versus la ciudad más carenciada, era "una expresión más del carácter clasista que evidencia la metrópoli” (p. 63).

\section{FIgura I | Piscina Chacarillas}

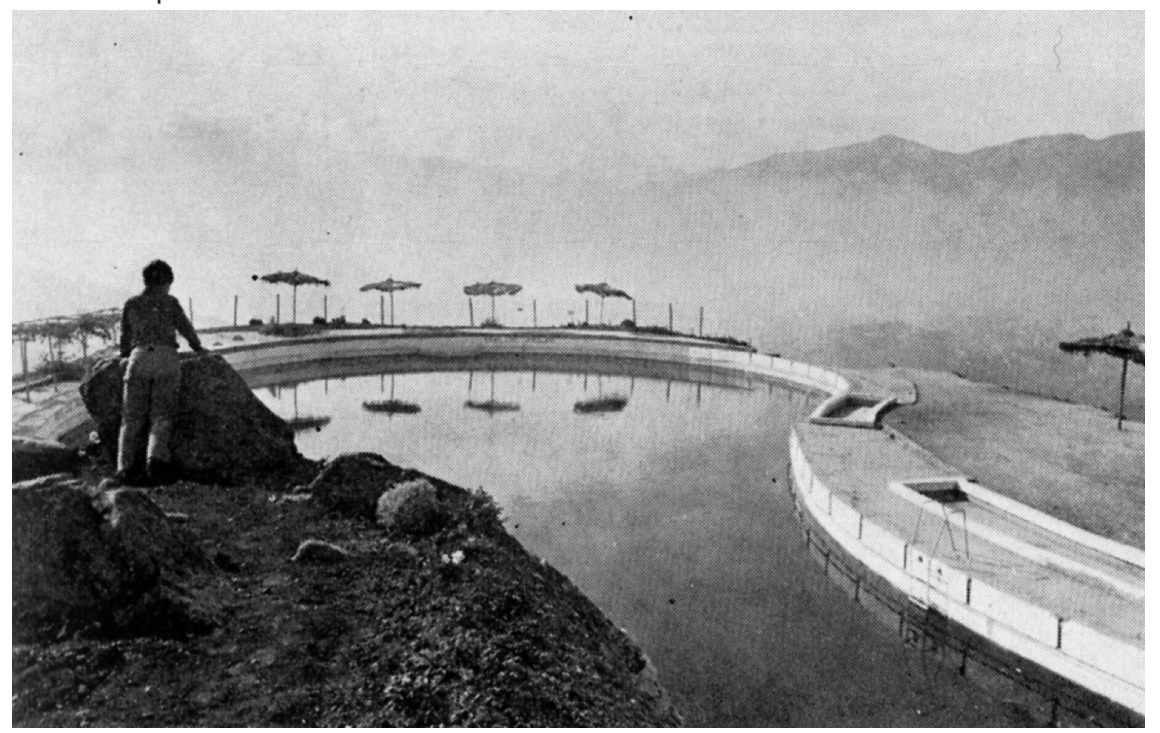

FUENTE: REVISTA $A U C A, 2$ I (I97I)

$2 \longdiv { \text { Datos extraídos de un folleto promocional del ministerio recuperado desde el archivo personal de } }$ Miguel Lawner. 
El mandato del gobierno conminaba a la premura, y para el desarrollo del parque O’Higgins hubo de instalarse una denominada "oficina en campaña" integrada por profesionales que debían proyectar in situ y en paralelo a la ejecución de las obras (CORMu, 1973). Esto obedecía a que el parque seguiría el sistema de "ejecución directa”, es decir, la contratación de mano de obra, dirección de trabajos y adquisición de materiales serían comandadas por la misma cormu. De este modo, las obras ejecutadas mediante ese sistema servían también como un programa de empleo estatal. ${ }^{3}$ La presencia de un gran contingente obrero, sumado a la presión por apurar los trabajos, hizo que el proyecto arquitectónico siguiera un concepto general, pero se resolviera en lo particular obedeciendo a decisiones de momento. El equipo fue liderado por los arquitectos Raúl Bulnes, en los aspectos de gestión y construcción, y Carlos Martner, precursor y académico de la arquitectura del paisaje moderno en Chile. Todos los participantes del proyecto que fueron entrevistados coincidieron en recordar una "mística" subyacente a la experiencia, que trascendía el cometido profesional y alcanzaba la esfera de los afectos y las emociones.

\section{FIgURA 2 | Planta del anteproyecto, parque O’Higgins}

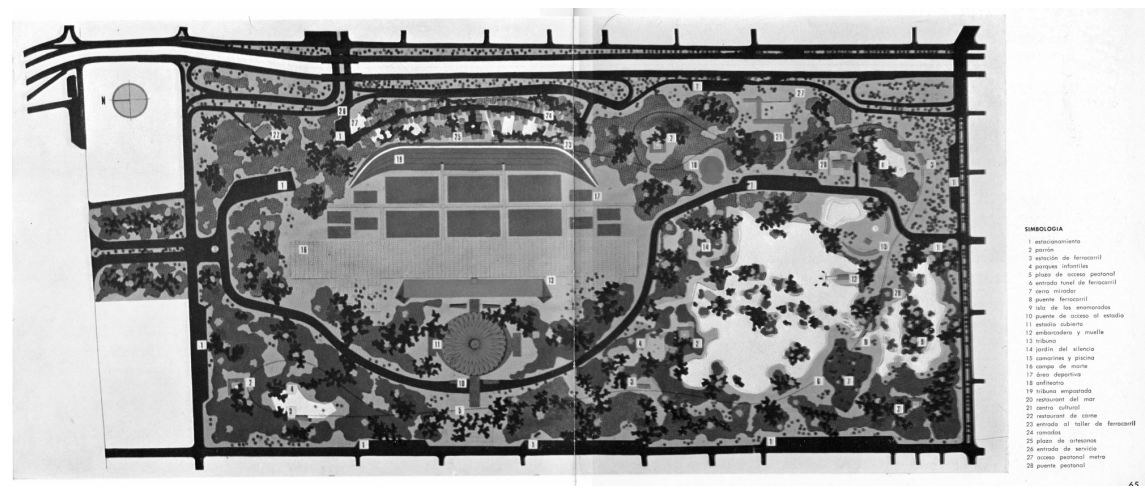

FUENTE: REVISTA $A U C A, 2$ I (I97I)

Se contó con la asesoría de dos expertos cubanos, Antonio Quintana y Ricardo Berrayarza, cuya misión fue transmitir la experiencia de la ejecución del parque Lenin en La Habana, implantando un modelo tipológico de parque popular (Quintana \& Berrayarza, 1971). El anteproyecto fue desarrollado bajo la influencia de los arquitectos cubanos, siguiendo un diseño plasticista y radical, con una estética próxima a la del Movimiento Moderno, que prácticamente borraba las huellas del trazado decimonónico original (Figura 2). Por el contrario, los croquis del arquitecto Carlos Martner que acompañaron esta etapa del diseño, eran prolíficos en anécdotas y

3 Cuando no se cita explícitamente otro documento, la información respecto al proceso de remodelación del parque proviene de entrevistas efectuadas a distintos funcionarios de la oficina en campańa y del municipio, realizadas entre abril de 2009 y mayo de 2010. Se entrevistó a Raúl Bulnes, arquitecto jefe de proyecto; Carlos Martner, arquitecto; Raúl Jiménez, administrativo; Myriam Beach y Virgina Plubins, arquitectas; Tiziana Brandolini, paisajista; Alby Rubio, arquitecta y funcionaria municipal. 
situaciones pintorescas: botes, trenes en miniatura, banderines y muchedumbres (Figura 3). Entre ambas representaciones se encontraba el resumen del concepto de parque popular: un espacio sintético y antitético a la estética recargada y narrativa del romanticismo del siglo xIx, pero, a la vez, nutrido de un programa recreativo concreto. Esta misma fórmula se desarrolló en el volkspark alemán de entreguerras: una tipología que debía resignificar los elementos frívolos y aristocráticos del "salón verde" y ponerlos al servicio de la recreación practicada (Maas, 1981; Venier, 1981). Así, las lagunas navegables, las grandes plazas de juegos infantiles, las praderas ideadas para el picnic y los grandes restaurantes se distribuían en diseńos pragmáticos, que, si bien a primera vista no parecían diferir mucho del modelo anterior, revolucionaban el programa que hasta entonces había dominado el diseño de áreas verdes. Inaugurado el 22 de abril de 1972, el parque Lenin de La Habana, en su fabulosa extensión de 472 hectáreas se hacía cargo sin problemas tanto del concepto de radicalidad estética como de la activación programática. Sobre un manto de paisaje naturalista, sin demarcaciones ni trazados geométricos que lo interrumpieran, se dispuso una serie de pabellones blancos de hormigón prefabricado, de arquitectura señera y con vitrales de colores que albergaban programas como un anfiteatro; un acuario, una serie de quioscos cafeterías y restaurantes (Martín Zequera, 2013). Entre estos últimos, destacó el llamado "Las Ruinas", de Joaquín Galván, por su particular integración entre vegetación y arquitectura brutalista.

\section{FIgura 3 | Croquis del pueblito, parque O’Higgins, arquitecto Carlos Martner}

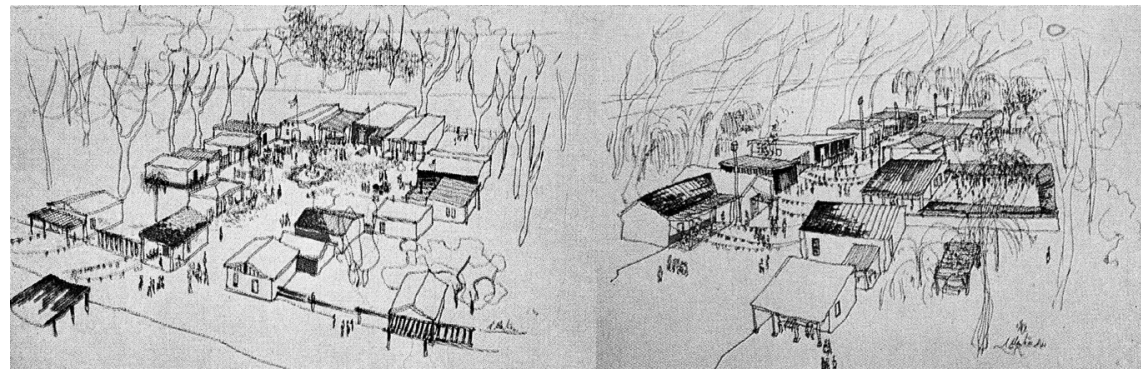

FUENTE: REVISTA $A U C A, 2$ I (I97I)

El modelo abstracto que se ideó en la etapa de anteproyecto fue modificado sustancialmente cuando los asesores cubanos se fueron de Chile y el diseño del parque quedó en manos de los procesos del equipo en terreno. El trazado y los elementos decimonónicos, como la laguna central con sus jardines bucólicos y el quiosco de los músicos, fueron restaurados para recuperar su diseño original (Figura 4). Se inyectó recursos a uno de los componentes más particulares de la propuesta: el denominado pueblito. Este aparecía ya en el anteproyecto como una "calle de las ramadas", instalaciones gastronómicas estacionales propias de la cultura popular y las celebraciones patrias. En la obra final, el conjunto exhibió un despliegue arquitectónico y tipológico mucho mayor, que superaba el referente popular tan ligero como anodino. Se buscó construir una narración espacial de la arquitectura típica 
del país, desde el extremo norte al centro sur, con una serie de comedores en los que el público podía degustar también la geografía culinaria de Chile. Mención especial merece el magnífico escenario que el Gobierno Popular construyó para los desfiles anuales del Ejército sobre la elipse del Campo de Marte, que tenían lugar allí desde 1842. Según Lawner, la pavimentación de una gruesa losa armada de 65 metros de ancho por 620 de largo y la ampliación de las graderías hasta una capacidad de 25.000 espectadores fueron una obstinación del propio presidente Allende para honrar a las Fuerzas Armadas.

\section{FIgURA 4 | Planta del proyecto definitivo, parque O'Higgins}

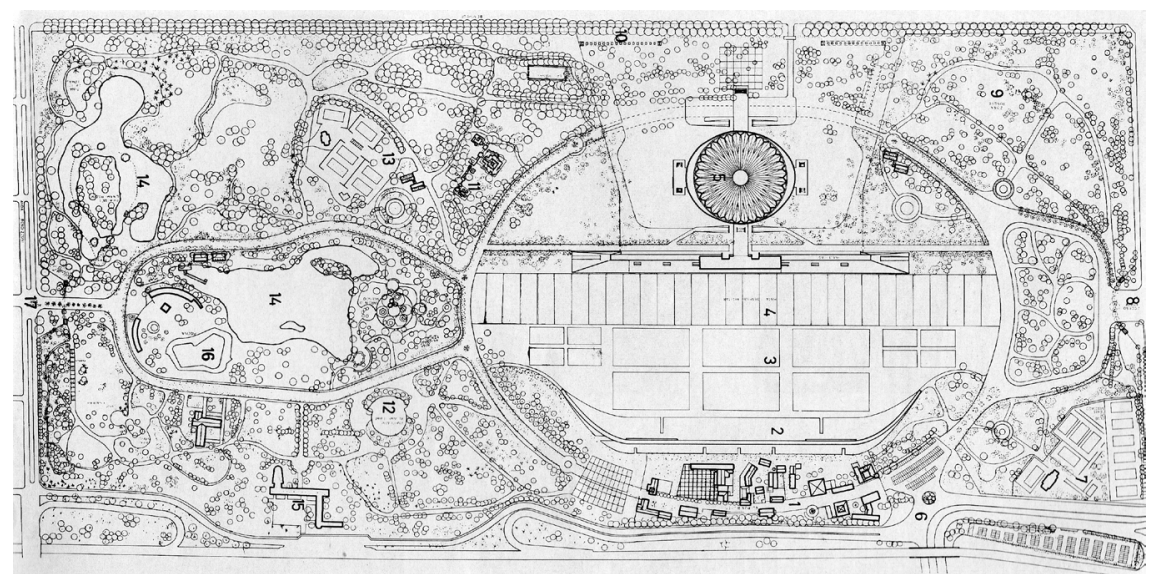

FUENTE: REVISTA $A U C A, 24 / 25$ (I973)

El parque se alhajaba también con dos grandes plazas de juegos infantiles de madera diseńados ad hoc, cuya economía material no opacaba la creatividad de su arquitectura. Un centro cultural -que recuperaba la arquitectura del malogrado Hogar Parque Cousiño ${ }^{4}$-, un anfiteatro abierto, un centro artesanal en el pueblito y una serie de canchas deportivas y camarines, completaban el repertorio. Se pensaba que el parque y su nutrida programación recreativa, culinaria, deportiva y cultural debían quedar a cargo de una repartición del Estado, desplazando a la Municipalidad de Santiago, que hasta entonces había tenido el control del predio (CORMu, 1971b). Del mismo modo, se aseguraba con eso que la oferta de consumo se mantuviera en precios accesibles.

En resumen, la versión chilena del modelo de parque popular resultó en un programa de actividades que se desplegaba sobre una superposición de estéticas racionalistas y pintorescas, entretejiéndose el jardín romántico con la cultura popular rural. Los usos fueron orientados a un pueblo que también fue figurado de forma modélica: el obrero junto a su familia. La carga de diseño se estimaba en 
60.000 personas (Cousin, 1974), un parque masivo y utilitario cuyo equipamiento permitía acoger una jornada completa de ocio. La imagen más representativa de este ensamblaje cultural y la adaptación del modelo de referencia se sintetiza en un reportaje promocional que muestra la laguna, dispositivo por excelencia del paisajismo ornamental romántico, rodeada ahora de grandes muchedumbres populares, usando el paisaje otrora contemplativo, con el cuerpo distendido, recostadas sobre las orillas en una postura que fue prohibida en los reglamentos del siglo XIX (Figura 5).

FIGURA 5 | Fotografía del reportaje "Un lugar feliz"

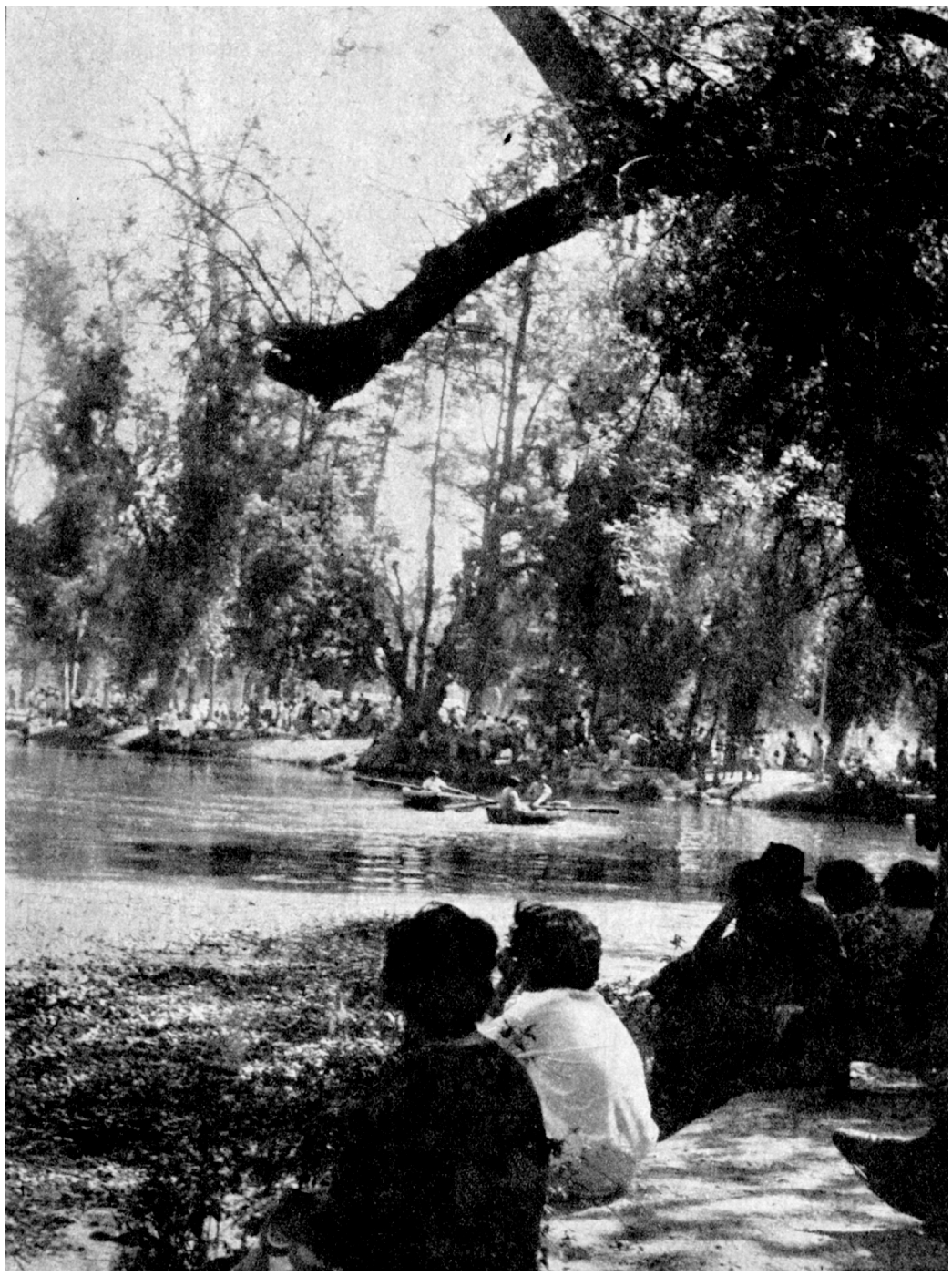

FUENTE: REVISTA RAMONA, 55 (I 4 DE NOVIEMBRE DE I972), P. I 2 


\section{Los parques de la Transición}

El periodo denominado de Transición a la Democracia ${ }^{5}$ fue un proceso de extrema tensión. Los militares golpistas y muchos actores políticos que formaron parte de la dictadura permanecieron en posiciones de poder en el Ejército y en el Congreso. Como relata Cavallo (1998), el proceso estuvo marcado por vetos tácitos pero ineludibles, y "tradiciones" que pesaban más que la ley. El gobierno de Patricio Aylwin duraba cuatro años, sin posibilidad de reelección, y tenía como misión afianzar la institucionalidad democrática y alcanzar la reconciliación, un concepto cuyas raíces llegaban a lo más profundo de los crímenes y violaciones a los Derechos Humanos que perpetró el régimen cívico-militar, y la posibilidad de establecer una verdad y una justicia "en la medida de lo posible". ${ }^{6}$

Además de los crímenes contra la vida y la integridad de las personas, el gobierno de Pinochet dejó un oscuro legado en la configuración urbana de la barriada de la ciudad de Santiago. Es un hecho que la crisis de la periferia precaria ya se había iniciado antes -con la Operación Sitio (1965-1970), la proliferación de campamentos o "callampas" durante el gobierno de la Unidad Popular ${ }^{7}$ y, en general, con la mayoría de las iniciativas del Estado de Chile desde la creación de la cartera de vivienda (Hidalgo, 2004)-, pero en los años noventa el discurso tendió a atribuir al régimen el descalabro. En efecto, 1979 había sido un ańo clave para la configuración de la capital: por una parte, se promulgó una Política Nacional de Desarrollo Urbano (PNDU) que seguía tres principios: i) el suelo no era un recurso escaso, ii) su uso debía definirse según la mayor rentabilidad, y iii) según medidas flexibles que se adaptaran a los requerimientos del mercado (Morales et al., 1990). Al mismo tiempo, se iniciaba un agresivo programa de erradicación de campamentos (19791985) que liberaba para el mercado inmobiliario los terrenos ocupados, trasladando a las familias a viviendas definitivas (Figura 6). Se trató de una política basada en transformar a los obreros en propietarios y disolver asentamientos irregulares. Pero,

5 El periodo de Transición, en su versión más abreviada, comprende entre el plebiscito de 1988 y el traspaso del mando de Pinochet a Aylwin en 1990; sin embargo, el gobierno de este último se denominó también de Transición (1990-1994), por ciertas restricciones particulares a su periodo. Si bien no hay consenso en el mundo académico respecto de cuándo la Transición habría terminado (o si hubiera concluido alguna vez del todo), para este escrito se utiliza el término para referirse a los primeros gobiernos posdictatoriales, especialmente el de Aylwin.

6 "La conciencia de la nación exige que se esclarezca la verdad, se haga justicia en la medida de lo posible -conciliando la virtud de la justicia con la virtud de la prudencia- y después venga la hora del perdón”. Esta cuña del presidente Aylwin fue pronunciada el 21 de mayo de 1990 y se convirtió en una frase símbolo del periodo de transición. Representaba las profundas limitaciones políticas que tenía el proceso en un ambiente violentado por atentados y asesinatos cometidos por las células subversivas que se habían opuesto al régimen, así como pronunciamientos y ejercicios amenazantes por parte del Ejército. Véase: Legislatura 320a, Ordinaria, Sesión del Congreso Pleno, lunes 21 de mayo de 1990, IV Mensaje Presidencial, Archivo Fundación Patricio Aylwin. Véase también en https://www.camara.cl/camara/doc/archivo_historico/21 mayo_1990.pdf

7 La Operación Sitio fue un sistema de otorgamiento de terrenos semiurbanizados en propiedad para la autoconstrucción. Los campamentos o "callampas" se refieren a las ocupaciones de terrenos que se agudizaron con el gobierno de Allende y que recibían ese nombre por la velocidad con que se alzaban viviendas precarias en espacios baldíos entonces periféricos. 
con esto, se disolvieron también las redes sociales de las comunidades, originando una periferia vulnerable, desarraigada y desvinculada. Estas masivas operaciones, que desplazaron a unos 30.000 hogares, han sido ampliamente estudiadas y criticadas por la academia (véase especialmente el estudio de Morales et al., 1990) y calificadas, incluso, como un nefasto proceso de eugenesia urbana (Leyton, 2015) cuyas consecuencias son visibles hasta el día de hoy. La prioridad puesta en el déficit de vivienda se reflejó en poblaciones carentes de espacios públicos y equipamiento. Al mismo tiempo, se subdividieron las comunas generando deliberadamente zonas administrativas de pobreza homogénea y concentrando a los erradicados en unos pocos municipios (Hidalgo, 2004; Morales et al., 1990). A partir de la promulgación de la PNDU de 1985, la visión sobre la liberalización del mercado de suelo cambió y se comenzó con un programa de "radicación de campamentos" que, a la inversa del anterior, buscaba proveer de equipamiento e infraestructura básica a las callampas, mediante una estrategia de autoconstrucción. Pero las radicaciones operaron sobre los mismos territorios de pobreza que ya se habían conformado con las operaciones anteriores, consolidando aún más la segregación en el espacio (Hidalgo, 2004). En resumen y en consideración a sus políticas urbanas, puede decirse que la dictadura representó para la Concertación ${ }^{8}$ lo que la Colonia a la República: un epítome de la barbarie.

Durante la primera década de gobierno democrático se mantuvo el déficit habitacional en 900.000 familias, fruto, principalmente, del allegamiento. Solo después de los dos primeros gobiernos (1998), se logró disminuir en aproximadamente un tercio. Ampliando el modelo de subsidio a la demanda impuesto por la dictadura, se llegó a beneficiar en el periodo a más de medio millón de hogares (Hidalgo, 2004). Se buscó, sin embargo, que ese subsidio a la demanda volviera a poner en valor la postulación colectiva (Etchegaray, 1997). Institucionalmente se promovió una asociación público-privada, con un ministerio que se consideraba a sí mismo más facilitador que ejecutor (MINvU, 2004). A pesar de los logros cuantitativos de la política, la segregación social siguió operando, fundamentalmente por la incapacidad del Estado de adquirir terrenos para proveer vivienda mejor ubicada. Como señala Hidalgo (2004), la vivienda social provista en la Transición siguió los mismos patrones de localización que se tenían desde la Operación Sitio. En este escenario, surgió el objetivo de reparar los entornos carenciados con programas como el de Mejoramiento de Barrios, de Equipamiento Comunitario, de Pavimentos Participativos y el de Parques Urbanos.

El Programa de Parques Urbanos se inició en Santiago en 1992, bajo la dirección del ministro Alberto Etchegaray. Ampliado después de 1994 a escala nacional, el Programa llegó a construir en una sola década 226 hectáreas de áreas verdes distribuidas en 56 proyectos. Los recuentos en documentos oficiales presentan variaciones, pero el logro de la política se medía entonces destacando que lo realizado en Santiago en una década había sido equivalente a todas las áreas verdes que se habían

El término "Concertación" es el nombre con que se refiere a la "Concertación de Partidos por la Democracia”, conglomerado político que se forma para derrotar al régimen y que luego ocupó el poder por los siguientes veinte ańos. 
construido en la capital hasta el momento, desde la creación de la Quinta Normal, el primer parque público, en 1838. El Programa debía operar sobre sitios de propiedad pública o comunal y, aunque hubo intenciones iniciales de conformar estrategias que tejieran morfológicamente la ciudad, sirviéndose del río Mapocho y el zanjón de la Aguada (Schmidt, 1993), en la práctica resultó una sumatoria de proyectos puntuales. Fue una política agresiva y de ejecución rápida (Figura 7, Tabla 1 y Tabla 2). Así, en el año 1993 se inauguraron los parques de La Bandera en San Ramón, Santa Mónica en Recoleta, Lo Varas en Renca y la Arboleda El Cortijo en Conchalí.

FIGURA 6 | Diagrama de las erradicaciones (1979-1985)

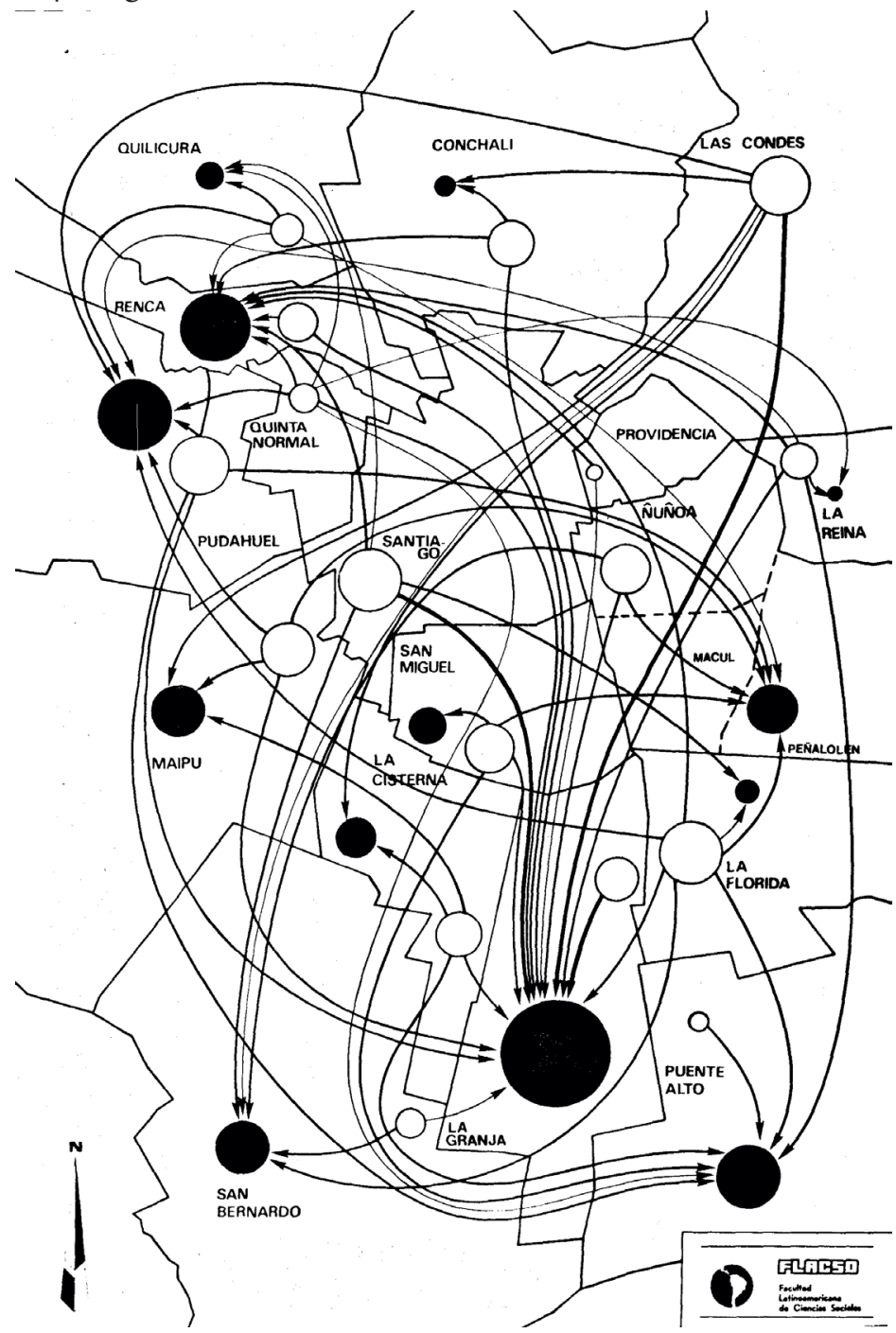

FUENTE: MORALES ET AL. (I990), P. 2 I 
FIGURA 7 | Parques realizados en Santiago, periodo 1992-2002

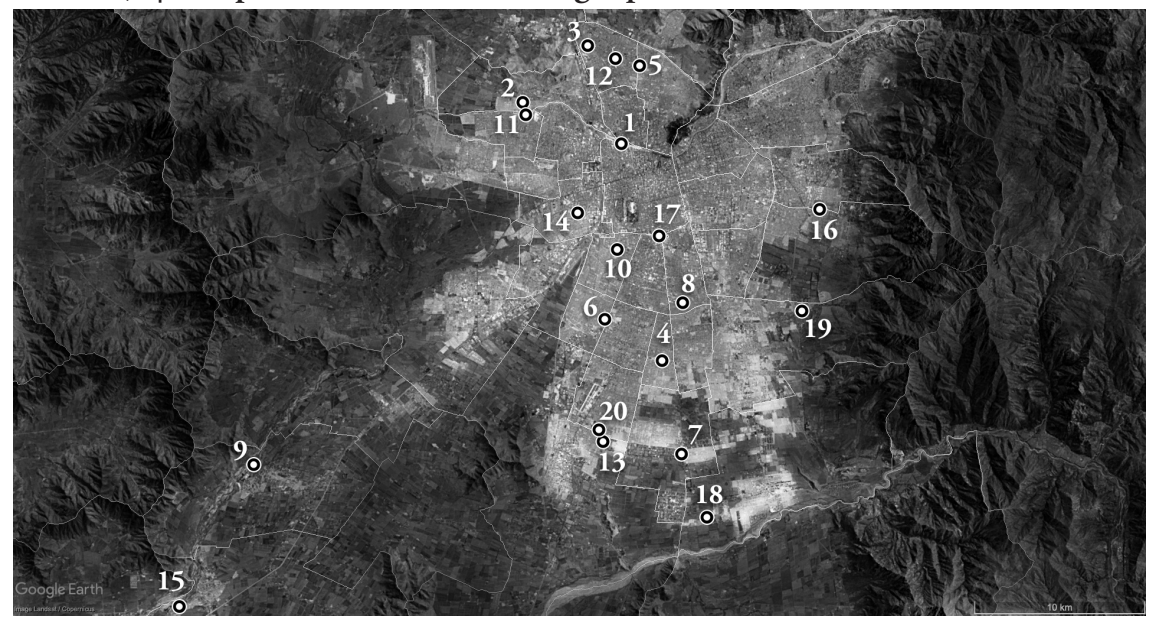

NOTA: VÉASE TABLA I PARA IDENTIFICACIÓN

FUENTE: ELABORACIÓN PROPIA SOBRE FOTOGRAFÍA AÉREA DEL 30 DE DICIEMBRE DE I990, LANDSAT COPERNICUS, GOOGLE EARTH

TABLA I | Parques realizados en la región Metropolitana, periodo 1992-2003

\begin{tabular}{|c|c|c|c|c|}
\hline AÑo & COMUNA & N. ${ }^{\circ}$ & PROYECTO & SUPERFICIE (HA) \\
\hline 1992 & Santiago & 1 & Los Reyes* & 30 \\
\hline \multirow{3}{*}{1993} & Renca & 2 & Lo Varas & 2 \\
\hline & Conchalí & 3 & El Cortijo & 1,9 \\
\hline & San Ramón & 4 & La Bandera & 14,9 \\
\hline 1994 & Recoleta & 5 & Santa Mónica & 6,3 \\
\hline \multirow{4}{*}{1995} & Lo Espejo & 6 & Violeta Parra & 2,8 \\
\hline & La Pintana & 7 & Mapuhue & 7 \\
\hline & San Joaquín & 8 & La Castrina & 9,3 \\
\hline & Peñaflor & 9 & El Trapiche & 8,9 \\
\hline \multirow{2}{*}{1996} & Pedro Aguirre Cerda & 10 & André Jarlan (ex La Feria) & 11,7 \\
\hline & Cerro Navia & 11 & Mapocho Poniente & 7 \\
\hline \multirow{2}{*}{1997} & Conchalí & 12 & Paseo Pedro Fontova & 2,2 \\
\hline & San Bernardo & 13 & Martín de Solís & 1,7 \\
\hline \multirow{2}{*}{1998} & Estación Central & 14 & Bernardo Leighton (ex Las Américas) & 7 \\
\hline & Talagante & 15 & Octavio Leiva (ex Pozo Bráncoli) & 3,5 \\
\hline 1999 & Peñalolén & 16 & Parque por la Paz (ex Villa Grimaldi) & 1,2 \\
\hline \multirow{3}{*}{2001} & San Miguel & 17 & $\begin{array}{l}\text { Víctor Jara (ex Intercomunal Sur) I } \\
\text { etapa }\end{array}$ & 1,2 \\
\hline & Puente Alto & 18 & La Cañamera I & 3 \\
\hline & La Florida & 19 & Quebrada de Macul & 9,2 \\
\hline 2003 & El Bosque & 20 & Lo Blanco & 2 \\
\hline \multicolumn{4}{|c|}{ Total: 20 parques } & 132,8 \\
\hline
\end{tabular}

* El PROYECTO LOS REYES (I992) CONTEMPló FINANCIAMIENTO MUNICIPAL AGREGAdo A LOS FONDOS REGIONALES

FUENTE: ELABORADO A PARTIR DE SEGOVIA (2005) 
TABLA 2 | Parques realizados en regiones, periodo 1992-2002

\begin{tabular}{|c|c|c|c|c|}
\hline REGIÓN & COMUNA & AÑo & PROYECTO & $\begin{array}{c}\text { SUPERFICIE } \\
\text { (HA) }\end{array}$ \\
\hline \multirow{6}{*}{ III } & Vallenar & 1994 & Río Huasco & 2 \\
\hline & Copiapó & 1995 & Forestación Áreas Populares & 1,4 \\
\hline & Copiapó & 1996 & Parque Sector Norte & 1,4 \\
\hline & Caldera & 1997 & Plaza Bellavista & 1 \\
\hline & Copiapó & 1999 & El Palomar & 1 \\
\hline & Copiapó & 2000 & El Palomar II & 2 \\
\hline \multirow{2}{*}{ IV } & Coquimbo & 1997 & O’Higgins & 3,8 \\
\hline & La Serena & 1999 & Lambert I etapa & 2 \\
\hline \multirow{4}{*}{ V } & Quillota & 1997 & Aconcagua & 4 \\
\hline & La Calera & 1997 & La Calera & 5 \\
\hline & Viña del Mar & 1999 & Forestal Alto & 6 \\
\hline & Los Andes & 1999 & O’Higgins & 5 \\
\hline \multirow{4}{*}{ VI } & Rancagua & 1994 & Parque Urbano Comunal (habilitación) & 14,5 \\
\hline & Rancagua & 1995 & Balneario Cachapoal & 4 \\
\hline & Rancagua & 1996 & Parque de la Juventud & 2 \\
\hline & Chimbarongo & 1997 & Parque de los Poetas & 1,2 \\
\hline \multirow{4}{*}{ VII } & Curicó & 1996 & Santa Fe & 5 \\
\hline & Talca & 1997 & Piduco Norte & 8 \\
\hline & Curicó & 1998 & Cerro Condell & 9 \\
\hline & Talca & 1999 & Estero Piduco & 3 \\
\hline \multirow{2}{*}{ VIII } & Talcahuano & 1999 & Cerro Amarillo & 2,23 \\
\hline & Talcahuano & 2000 & Las Hortensias & 3,65 \\
\hline \multirow{4}{*}{ IX } & Temuco & 1996 & Río Cautín & 5 \\
\hline & Loncoche & 1998 & Santa Lucía & 5 \\
\hline & Temuco & 1999 & Los Pinos & 5,5 \\
\hline & Temuco & 1999 & Plaza Teodoro Schmidt & 1 \\
\hline \multirow{3}{*}{$\mathrm{X}$} & Valdivia & 1998 & Krahmer I etapa & 2,3 \\
\hline & Valdivia & 1999 & Krahmer II etapa & 2,1 \\
\hline & Puerto Montt & 1999 & La Paloma I etapa & 5 \\
\hline XI & Coyhaique & 1996 & Las Lumas & 3,7 \\
\hline
\end{tabular}

FUENTE: ELABORADO A PARTIR DE ÁBALOS Y LEÓN (2OOI)

Los objetivos iniciales declarados en el Programa -contribuir a la calidad de vida y a la descontaminación- eran de una neutralidad pragmática y no hacían referencia a la problemática política, urbana ni social (Segovia, 2005). Sin embargo, en su forma de implementación y discursos paralelos, se podía entender un cometido más complejo. La estrategia de localización en sectores especialmente vulnerables y degradados aparecía declarada y se planteaba como una acción estatal que podía complementar y equilibrar las obras de parques municipales que en el periodo también se desarrollaban en el sector de alta renta, como el Inés de Suárez (Providencia, 1995) y el Intercomunal -actual Padre Hurtado- (La Reina, 1992-1993). El ministro Etchegaray (1997) planteaba una relación directa entre la ciudad y el concepto de 
democracia, señalando que la primera era un "vehículo privilegiado" para generar la segunda, y afectándola directamente en su calidad: "Cuando la ciudad es 'no democrática', en términos de que el nivel de acceso a los servicios, a la infraestructura, a la imagen que los ciudadanos que en ella habitan tienen, hace prácticamente imposible la idea de democracia”. Mientras el acceso a la vivienda era un asunto de recomponer equidad, el espacio público era el lugar que "constituye la expresión física, espacial, de la posibilidad de esa construcción democrática” (p. 9). Como señala Francisco Schmidt (1993), uno de los impulsores del Programa, se buscaba crear "espacio público" más que "áreas verdes" (p. 21). Al igual que en el proyecto del parque O'Higgins, se pensaba que la función de los parques era la recreación de las personas, aunque la programación era mucho menos dirigida y específica que en el modelo de parque popular. Los parques debían contar, eso sí, con mobiliario abundante, baños, juegos infantiles y de agua. La posibilidad de utilizar los parques urbanos como una política de reparación social, movilizó los proyectos.

Considerando lo anterior, los parques debían desempeñar una función de orden simbólico muy compleja y ambiciosa: reforzar en el imaginario colectivo la identidad de lugares vulnerables y postergados. Para ello, el Programa incorporó mecanismos de participación ciudadana vinculados al diseño. Por una parte, se esperaba reforzar el sentido de pertenencia de los usuarios y asegurar una buena conservación de los parques en el tiempo, lo que, unido a una administración centralizada, produjo finalmente muy buenos resultados. Pero, además, se quería empoderar a los usuarios involucrándolos en el proceso. Schmidt (1993) declaraba que "la construcción del Espacio Público en la ciudad, contribuye a elevar a la persona, del estado de mero individuo a ciudadano" (p. 21). Los parques actuaban, así, como herramientas de formación cívica.

El diseño de parques urbanos había sido, hasta entonces, una práctica poco común en Chile. Por ello, el Programa hubo de establecer relaciones con la academia y las agrupaciones profesionales para convocar al diseńo de los proyectos. El Instituto Chileno de Arquitectos Paisajistas (ICHAP) había sido recientemente fundado en 1989 y se transformó en el nodo articulador ideal para conformar los distintos equipos proyectistas. Grupos integrados por arquitectos como Carlos Martner, Elizabeth Huyghes, Francisco Schmidt, Hilda Carmona y Myriam Beach asumieron uno o más casos de trabajo, los que se desarrollaron en forma paralela y siempre ceñidos a un estrecho margen presupuestario (Beach, 1996; Segovia, 2006).

La psicóloga Cecilia Philippi se asoció a la arquitecta Catalina Bosch para implementar un método de diseño participativo que se aplicó en el desarrollo de siete proyectos del Programa (Philippi \& Bosch, 1996). Se buscaba que la comunidad involucrada no solo diera indicios de los requisitos programáticos de los parques sino que, realizada ex ante, la participación pudiera informar el proceso de diseño en categorías bastante más abstractas. Se buscó definir parámetros de orden, geometría y otras preferencias estéticas que los usuarios pudieran identificar y expresar. El método de trabajo fue completamente experimental, basado en medios de representación. En talleres específicos para cada género y edad, los futuros usuarios dibujaban cómo imaginaban el parque y valoraban imágenes de referencia (Figura 8). De ahí se traducían los resultados en características de diseño que informaron el 
trazado de los parques Santa Mónica, Arboleda El Cortijo, André Jarlan, Mapuhue, Bernardo Leighton y La Bandera. Sin embargo, como señala Segovia (2005), el proceso de participación no fue sistemático ni implementado con la misma metodología en todos los casos, y la participación solo se incluyó dentro de los objetivos en la reformulación del Programa recién el año 2000.

Como observa la misma autora en la evaluación del Programa, los parques no tuvieron un impacto de recuperación urbana en términos morfológicos; es decir, el entorno degradado no consiguió renovarse y los jardines urbanos se mantuvieron como una suerte de oasis delimitado. En muchos de estos parques los usuarios expresaron también percepción de inseguridad, pero su uso intensivo y el reconocimiento de su calidad parece un consenso (Segovia, 2005). Sostenida en el marco teórico de intelectuales como Jordi Borja, Fernando Carrión y Manuel Castells, la evaluación que hace Segovia $(2005,2006)$ del Programa destaca su capacidad de intervenir en la esfera cívico-política, como antídoto a la fragmentación y alienación propias de la cultura del consumo y la globalización del capital. Como señala la autora, la intervención para la mejora del espacio público colabora en "acrecentar el capital físico y el capital social en la ciudad” (Segovia, 2006, p. 1). Determina la forma de vivir y relacionarse, ayuda a subsanar la sensación de seguridad, segregación y abandono, y puede disminuir la fricción en áreas conflictivas (Segovia, 2005). Se trata de una función simbólica tanto o más relevante que la funcional, que explica el rol político del parque urbano en la ciudad global en las postrimerías del siglo xx. Esta función simbólica se sostiene en la creencia de la posibilidad de transferir al espacio un discurso político.

\section{FIgURA 8 Taller de diseño participativo}

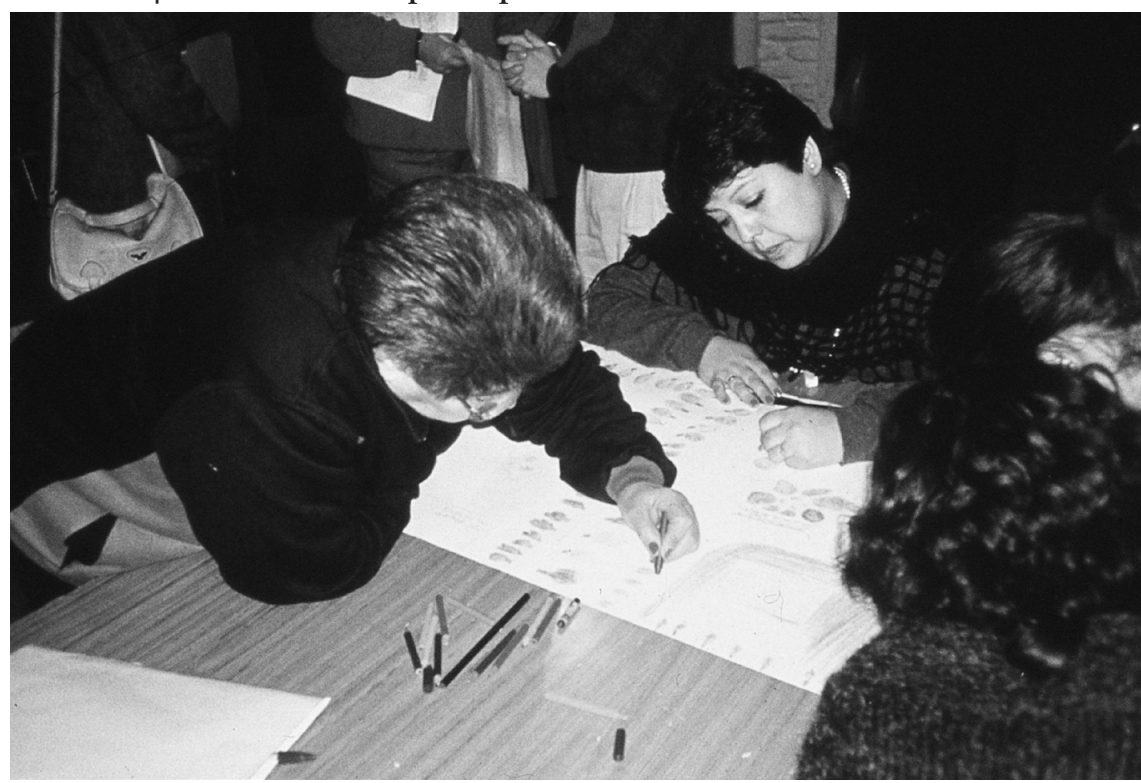

FUENTE: ARCHIVO AUTORA 


\section{Conclusión: reivindicación y reparación}

Los parques pueden ser comprendidos como pequeños fragmentos de utopía, territorios urbanos donde la sociedad proyecta sus ideales políticos, sociales y culturales respecto de cómo debe ser la vida en común. La "vía chilena”, las formas particulares y adaptadas de emprender ambiciosos proyectos políticos, como la construcción de una forma democrática de socialismo y la derrota pacífica y democrática de una dictadura, tienen su correlato también en experimentos híbridos de urbanización, cargados de cometidos simbólicos, negociaciones, apropiaciones y adaptaciones paulatinas. Así, puede decirse que el parque O'Higgins de Allende fue concebido como un instrumento de reivindicación popular. Una conquista simbólica del pueblo que recupera para sí el parque emblemático del siglo XIX, pero que superpone un imaginario nuevo al paisajismo romántico, que tampoco es el traslado literal del modelo de referencia cubano. En el otro margen, el Programa de Parques Urbanos de Aylwin fue implantado como una estrategia de reparación social, cultural y espacial. La reparación mediante parques de una periferia pobre, dañada y postergada, también fue un gesto de justicia espacial en proceso de transición o, volviendo a parafrasear a Aylwin, una justicia espacial "en la medida de lo posible". La construcción paulatina de una reconciliación del ciudadano con su ciudad. La reparación, usada generalmente como un proceso de cierre del ciclo de la Memoria, constituye también un espacio relacional en donde la disputa del poder da forma a la ciudad (Montealegre \& Rozas, 2018). Operó también como una apropiación simbólica que tomó forma en los nuevos nombres que fueron recibiendo estos parques, rememorando personajes de la cultura política local, como Bernardo Leighton, el alcalde Octavio Leiva, Víctor Jara y Violeta Parra; conmemorando víctimas de la violencia de Estado, como el sacerdote André Jarlan o, definitivamente como un memorial de sitio, en el caso del Parque por la Paz, edificado sobre los restos del antiguo centro de detención y tortura Villa Grimaldi.

Otro aspecto que aparece al cotejar ambos casos estudiados y que es representativo de visiones implantadas desde la esfera del poder político, es un cierto paternalismo implícito en el modelo de los sujetos destinatarios. Se trata de familias, cuya figuración es aún más conservadora y evidente en el modelo de parque popular. Si bien es cierto que la permuta de la cantina por el jardín familiar estuvo presente en los orígenes reformistas del parque urbano, sí se puede observar un giro respecto a la figura más liberal, juvenil e individualista del flânneur decimonónico. En el parque del siglo $\mathrm{xx}$, la esfera doméstica se ha proyectado definitivamente sobre la funcionalidad recreativa del espacio público. El parque urbano ha evolucionado así de un espacio contemplativo pero social, a un parque funcional y práctico, acorde a la visión infraestructuralista de la ciudad que toma preponderancia desde los años cincuenta. En cambio, las nuevas tendencias actuales buscan recuperar sus funciones ecológicas, descargar los parques de actividades y recuperar su "inutilidad" (Kullmann, 2014).

En el caso del parque popular, profusa y ambiciosamente activado -como el Lenin y el O'Higgins- se observa mayor deterioro y dificultad en su sostenimiento. No solo se requería de un aparato estatal en exceso robusto para tomar a su cargo la 
administración de las actividades, sino una mística que comprometiera a un voluntariado creativo e interesado en mantener la cartelera cultural que requerían. ${ }^{9}$ Por su parte, los parques del Programa de los ańos noventa, mucho más sencillos en dotación programática aunque sus costos de conservación también fueron puestos en entredicho, lograron consolidarse como un modelo urbano exitoso que trascendió el color político.

Este ejercicio comparativo refuerza la hipótesis metodológica de arranque respecto a la funcionalidad de los parques como objeto de estudio para entender tanto la política urbana como los discursos políticos y culturales más amplios de los periodos. A la inversa, puede señalarse también que incorporar la interpretación y detección de los símbolos políticos resulta determinante para el estudio historiográfico de una pieza urbana y su comprensión y situación en el contexto. Es importante advertir que el parque no es una insignia socialista ni democrática per se. Como estudia Menazzi (2018), el verde público fue utilizado paralelamente por la dictadura argentina, no sin sus propias contradicciones. El instrumento es usado por distintos discursos y los calces con las técnicas y las estéticas no son perfectos. Como observan Ballent y Gorelik (2000), "no existe un carácter esencial en la arquitectura capaz de expresar contenidos políticos” (p. 7); y, podría agregarse, tampoco lo hay en los programas ni en los instrumentos específicos. Solo en la lectura confrontada entre discurso y forma es posible entender qué hay de uno en la otra, cómo se retroalimentan y, quizá lo más interesante, cómo se contradicen. Expresiva de esto es la errada asignación que hace el imaginario popular de la pavimentación de la pista de desfile militar del parque O'Higgins como una obra de Pinochet.

Es importante aclarar que el haber dejado a la dictadura fuera de este análisis, no implica que no se hayan realizado algunos parques urbanos en la ciudad de Santiago durante el periodo, que también son interesantes de estudiar. El caso del parque Araucano, construido sobre los terrenos del ex fundo San Luis en la comuna de Las Condes, hizo de pieza central a un proyecto urbano que tuvo como centro el retail y el desarrollo de oficinas de alta gama, construido sobre un conjunto de vivienda social emblemático (véase el trabajo sobre el shopping center de De Simone, 2018). También lo fue el parque Lo Errázuriz, primer vertedero que prometió convertirse en parque y que solo materializó ocho hectáreas en 1988 (véase el estudio del caso en la tesis de Quezada, 2016). Recién el año 2019, el Estado llamó a licitación de diseńo para proseguir con el reverdecimiento de las 32 hectáreas restantes, que se mantienen eriazas desde 1985. Y también viene al caso el poco estudiado parque Las Palmeras de Renca (1984), un recinto de 16 hectáreas cuya conservación recayó sobre el presupuesto municipal, que terminó prácticamente desbaratado y recién se encuentra buscando mecanismos de recuperación. Sin embargo, los símbolos políticos de cada uno de estos casos son particulares a la historia urbana específica de cada uno de los lugares.

En 1975, la Junta Militar promulgó el Decreto Ley N. ${ }^{\circ} 877$, en donde busca delegar "a cualesquiera otras Instituciones del Estado”, ya sea de forma integral o parcelada, la administración del parque O’Higgins, dando cuenta de cómo los exasperaba la ambiciosa complejidad programática. 
Las relaciones de política y estética durante la dictadura constituyen un proceso menos evidente y que requiere de un análisis más complejo, como lo ha planteado Silvestri (2000) respecto al proceso argentino. Los parques producidos entonces, sin ser completamente distintos a las estrategias anteriores y posteriores, obedecen cada uno a formulaciones muy particulares y hasta divergentes. Son, además, representantes de un régimen que no articuló - al menos declaradamente- un discurso estético. Por el contrario, la up y la Transición buscan una coherencia discursiva en sí mismas. En el segundo caso hay, además, una cierta voluntad de continuidad y filiación respecto a la primera, y un declarado contraste respecto a la dictadura, especialmente en lo tocante a la idea de ciudad. Entre las proyecciones del estudio del periodo de la Transición, resta incorporar un estudio en profundidad sobre el aparato humano de "técnicos, expertos y funcionarios" (Menazzi \& Jajamovich, 2019) detrás de esa producción. Así como se hizo en el caso de la up, es importante comprender los motivos de este aparato, así como la transferencia de saberes y la circulación de modelos urbanos en la década de los noventa.

\section{Referencias bibliográficas}

Ábalos, M. A. \& León, S. (2001). Parques terminados 1993-2000. Documento de Trabajo, División de Desarrollo Urbano (DDU), Ministerio de Vivienda y Urbanismo (MINVU), Chile.

Ballent, A. (2005). Las huellas de la politica: Vivienda, ciudad, peronismo en Buenos Aires, 19431955. Universidad Nacional de Quilmes.

Ballent, A. \& Gorelik, A. (2000). El Príncipe. Block, 5, 6-11.

Beach, M. (1996). Parque público urbano: Sus elementos de diseño. ARQ, (34), 31-38. https:// issuu.com/edicionesarq/docs/arq_34/

Capillé, C. (2018). Political theatres in the urban periphery: Medellín and the library-Parks Project. Bitácora Urbano Territorial, 28(2), 125-134. https://doi.org/10.15446/ bitacora.v28n2.69893

Cavallo, A. (1998). La historia oculta de la transición: Chile 1990-1998, memoria de una época. Grijalbo.

Choay, F. (1975). Haussmann et le système des espaces verts parisiens. Revue de L'Art, (29), 83-99.

Corporación de Mejoramiento Urbano (CORMu). (1971a). CORMU. AUCA, (21), 33-35.

Corporación de Mejoramiento Urbano (CORMU). (1971b). Parque O’Higgins - Remodelación parque Cousiño. AUCA, (21), 63-65.

Corporación de Mejoramiento Urbano (CORmu). (1973). Parque O’Higgins. AUCA, (24/25), 35-40.

Cousin, J. P. (1974). Remodelation du parc O'Higgins à Santiago du Chili. L'Architecture d'aujourd'hui, (175), 114-117.

De Simone, R.-L. (2018). Instalando la ciudad del consumo: El palimpsesto urbano del primer shopping mall chileno en el fundo San Luis, Santiago. EURE, 44(133), 91-112. http:// dx.doi.org/10.4067/s0250-71612018000300091 
Ernouf, A. A. \& Alphand, A. (1886). L'art des jardins. Parcs-jardins-promenades-étude historiqueprincipes de la composition des jardins-plantations-décoration pittoresque et artistique des parcs et jardins publics; traité pratique et didactique. ( $3^{a}$ ed.). J. Rothschild, Editeur. http://archive.org/details/lartdesjardinspa00erno

Etchegaray, A. (1997). Vivienda, democracia y equidad. En A. Etchegaray, F. Giraldo, J. Mejía \& J. McDonald, Las reformas sociales en acción: Vivienda (pp. 9-15). Naciones Unidas, Comisión Económica para América Latina y el Caribe.

Findley, L. (2005). Building change: Architecture, politics and cultural agency. Routledge. https:// doi.org/10.4324/9780203601495

Foucault, M. (1975/2018). Vigilar y castigar (Ed. Castellana, 2018). Siglo XxI.

Foucault, M. (1978a/1979). Microfisica del poder (Ed. Castellana, 1979). Ediciones de la Piqueta.

Foucault, M. (1978b/2006). Seguridad, territorio, población (Ed. Castellana, 2006). Fondo de Cultura Económica.

Foucault, M. (1984). Space, knowledge and power. En P. Rabinow (Ed.), The Foucault Reader (pp. 239-256). Pantheon.

Gorelik, A. (1998). La grilla y el parque. Espacio público y cultura urbana en Buenos Aires, 18871936. Universidad Nacional de Quilmes.

Hidalgo, R. (2004). La vivienda social en Santiago de Chile en la segunda mitad del siglo xx: Actores relevantes y tendencias espaciales. En C. De Mattos, M. E. Ducci, A. Rodríguez \& G. Yáńez, Santiago en la globalización: ¡una nueva ciudad? (pp. 219-241). Ediciones SUR - EURE Libros. http://www.sitiosur.cl/r.php?id=16

Kullmann, K. (2014). The usefulness of uselessness: Towards a landscape framework for unactivated urban public space. Architectural Theory Review, 19(2), 154-173. https://doi. org/10.1080/13264826.2014.967330

Lawner, M. (Ed.). (2008). Salvador Allende, presencia en la ausencia. LOM.

Leyton, C. (2015). Geopolítica y ciudad gueto: Erradicaciones eugenésicas en la Dictadura Militar. Santiago de Chile 1973-1990. En C. Leyton, C. Palacios \& M. Sánchez (Eds.), Bulevar de los pobres: Racismo cientifico, higiene, y eugenesia en Chile e Iberoamérica siglos XIX $y$ XX (pp. 339-365). Ocho Libros.

Maas, I. (1981). People's parks in Germany: City and culture in the open air. LOTUS International, $I$.

Martín Zequera, M. E. (2013). El Parque Lenin: Cuatro décadas después. Arquitectura y Urbanismo, 34(1), 98-110. https://www.redalyc.org/articulo.oa?id=376834402009

Menazzi, L. (2018). “Un nuevo paisaje urbano”. La producción de espacios verdes públicos durante la última dictadura cívico-militar en Buenos Aires. Clepsidra. Revista Interdisciplinaria de Estudios sobre Memoria, 5(9), 14-33. http://ppct.caicyt.gov.ar/ index.php/clepsidra/article/view/MENAZZI

Menazzi, L. \& Jajamovich, G. (2019). Saberes urbanos. Profesionales, técnicos, funcionarios y agencias estatales en la producción de ciudad. Teseo.

Ministerio de Vivienda y Urbanismo (minvu), Chile. (2004). Chile: Un siglo en políticas de vivienda y barrio. Pehuén. 
Montealegre, P. (2010). Jardín para el Pueblo: El imaginario de la Unidad Popular en el Parque O'Higgins [Tesis de Maestría]. Pontificia Universidad Católica de Chile. https://www. academia.edu/41614156/Jard\%C3\%ADn_para_el_Pueblo_El_Imaginario_de_la_ Unidad_Popular_en_el_Parque_OHiggins

Montealegre, P. (2017). La figuración de un jardin público: Urbanismo y agricultura en la construcción del Santiago moderno (1838-1875) [Tesis Doctoral]. Pontificia Universidad Católica de Chile. http://146.155.94.41/xmlui/handle/11534/22585

Montealegre, P. \& Rozas, V. (2018). Introducción. En P. Montealegre \& V. Rozas (Eds.), Disputar la ciudad: Sometimiento, resistencia, memorialización, reparación (pp. 7-16). Bifurcaciones.

Morales, E., Levy, S., Aldunate, A. \& Rojas, S. (1990, mayo). Erradicados en el Régimen Militar: Una evaluación de los beneficiarios. Documento de trabajo Programa FLACSO-Chile, número 448. FLACso Chile. http://flacsochile.org/biblioteca/pub/ memoria/1990/000226.pdf

Philippi, C. \& Bosch, C. (1996). Participación: una metodología. ARQ, (34), 26-30. http:// www.edicionesarq.cl/1996/arq-34/

Quezada, A. (2016). Territorialidad, participación y conflicto en el proceso de cierre del relleno sanitario Lo Errázuriz (1984-2005) [Seminario de Grado, Facultad de Filosofía y Humanidades, Departamento de Ciencias Históricas]. Universidad de Chile. http:// repositorio.uchile.cl/handle/2250/144239

Quintana, A. \& Berrayarza, R. (1971). Informe sobre el trabajo de paisajismo realizado por los técnicos cubanos, Arq. Antonio Quintana e Ing. Ricardo Berrayarza durante su visita a Chile invitados por el compañero Presidente, Salvador Allende Gossens. AUCA, (21), 66.

Raposo, A. (Ed.). (2001). Espacio urbano e ideologia: El paradigma de la corporación de la vivienda en la arquitectura habitacional chilena. 1953-1976. Universidad Central (Santiago de Chile), Facultad de Arquitectura y Bellas Artes, Centro de Estudios de la Vivienda.

Raposo, A. \& Valencia, M. (2004). Práctica política del diseño urbano. Notas sobre la vida institucional y labor de la Corporación de Mejoramiento Urbano, CoRmu. 1966-76. Revista INVI, 19(49). https://doi.org/10.4067/invi.v19i49.370

Schmidt, F. (1993). Programa de Parques Urbanos en Santiago. ARQ, (24), 21-25.

Segovia, O. (2005). Experiencias emblemáticas para la superación de la pobreza y precariedad urbana: Espacio público (Documento de proyecto, LC/W.60). Comisión Económica para América Latina y el Caribe (CEPAL). https://repositorio.cepal.org/bitstream/ handle/11362/3988/1/S2005071_es.pdf

Segovia, O. (2006). Experiencias emblemáticas para la superación de la pobreza y precariedad urbana: Espacio público - Resumen (Documento de proyecto, LC/W.60). Comisión Económica para América Latina y el Caribe (CEPAL). https://repositorio.cepal.org/ bitstream/handle/11362/3988/S2005071_es.pdf.txt

Silvestri, G. (2000). Apariencia y verdad: Reflexiones sobre obras, testimonios y documentos de arquitectura producidos durante la dictadura militar en la Argentina. Block, 5, 38-50.

Venier, A. (1981). Milk, meadow, water, brick - Story of the Hamburg Stadtpark. LOTUS International, $I$. 